\title{
Testing New Solutions for Eco-Driving: Haptic Gas Pedals in Electric Vehicles
}

\author{
Jaume R. Perelló1,2, Antoni Gomila1, Eva M. García-Quinteiro², Marta Miranda² \\ ${ }^{1}$ University of the Balearic Islands (UIB), Palma, Spain \\ ${ }^{2}$ Automotive Technology Centre of Galicia (CTAG), Pontevedra, Spain \\ Email: jaumer.perello@uib.eu
}

How to cite this paper: Perelló, J.R., Gomila, A., García-Quinteiro, E.M. and Miranda, M. (2017) Testing New Solutions for Eco-Driving: Haptic Gas Pedals in Electric Vehicles. Journal of Transportation Technologies, 7, 1-25.

http://dx.doi.org/10.4236/jtts.2017.71001

Received: September 12, 2016

Accepted: December 9, 2016

Published: December 12, 2016

Copyright () 2017 by authors and Scientific Research Publishing Inc. This work is licensed under the Creative Commons Attribution International License (CC BY 4.0).

http://creativecommons.org/licenses/by/4.0/

\section{Open Access}

\begin{abstract}
Reducing energy consumption has become a matter of increasing concern for electric vehicle owners. EcoDriver is a project funded by the European Commission, searching for new eco-driving solutions for reducing energy consumption in private and public transport. EcoDriver's main purpose is to teach efficient driving strategies and facilitate drivers' decision-making processes through several feedback modalities, in order to help increase driving efficiency and therefore reduce energy consumption. In the present study, the Full ecoDriver System combined with a haptic feedback gas pedal was tested in real driving conditions to give answers to some questions about its effectiveness, efficiency, workload and acceptability in an electric vehicle. The sample profile was composed by thirty young but experienced drivers. They had to drive around an open road track which allowed several possible scenarios such as curves, intersection or roundabout, speed limit changes and preceding vehicles. Average speed was registered on each lap, likewise other subjective measurements. The main results suggest that the efficiency benefits achieved while driving depend on the event type and the feedback modality provided. For instance haptic feedback seems to be especially indicated for roundabouts. In addition, the visual feedback provided by the FeDS nomadic device helps to save energy and learn eco-driving strategies. These outcomes indicate how several feedback modalities could facilitate the decision making process, changing driving behaviour, reducing energy consumption and increasing safety. These questions would help advance further research on eco-driving Intelligent Transport Systems and driving behaviour issues.
\end{abstract}

\section{Keywords}

Decision-Making, Eco-Driving, Electric Vehicle, Haptic Gas Pedals, Workload 


\section{Introduction}

Global warning and greenhouse gas emissions are topics of great interest nowadays all around the world. After industry, the transportation sector is the second-largest contributor to greenhouse gas emissions in the European Union, accounting for around one fourth of the total $\mathrm{CO}_{2}$ emissions [1].

Owing to this, energy efficiency in the automotive sector is currently a focus of research and industry activities. Besides technological innovations, drivers' behaviour is a potential area of improvement in order to increase vehicles' efficiency. Eco-driving is a recent campaign originated in Switzerland and Finland [2] and promoted by some European institutions whose main objective is teaching drivers an efficient driving style which allows them to reduce energy consumption and greenhouse gas emissions. There are different eco-driving strategies for Internal Combustion Engine (ICE) vehicles and Electric Vehicles (EV) because the characteristics of their power train efficiency are completely different [3] [4]. Some eco-driving strategies for EV have been proposed in the Energy Efficient Vehicles for Road Transport project (EE-VERT) [2] such as applying light but consistent pressure on the accelerator pedal, using the ECO mode for improved efficiency, applying early smooth braking which boosts regenerative braking, the use of Cruise Control (CC) to maintain steady speeds and using Recirculate Mode when Climate Control is on. These eco-driving strategies have been shown to produce reductions in energy consumption in several studies [5] [6]. In particular, for EV, due to their limited battery power duration, saving energy to increase vehicle autonomy has become a mandatory issue that can increase anxiety and cognitive workload for EV drivers, a phenomenon known as "Range Anxiety" [5]. Thus, EV owners are more concerned with their consumption. They fear that their vehicle will have insufficient range to reach its destination and would thus leave the vehicle's occupants stranded.

EcoDriver-supporting the driver in conserving energy and reducing emissions-is a four-year European project that supports the driver in adopting an eco-driving behaviour adapted to them and to their vehicle's characteristics through different feedback applications (for more details view [7] [8] [9] [10] [11]).

The Automotive Technology Centre of Galicia (CTAG) for the implementation of new technologies and the encouragement of research, development and innovation, is an ecoDriver test site location that has designed different Field Operational Tests (FOT) to validate the working of three configurations based on two ecoDriver systems: the Android ecoDriver System and the Full ecoDriver System (FeDS). One of these tests was carried out by the authors of this project in close collaboration with CTAG. This study employed the Full ecoDriver System complemented by a haptic gas pedal to enhance the feedback provided to the user.

Smart driving systems, and particularly eco-driving systems, are a potentially achievable and efficient measure for private transport to contribute saving energy and consequently reducing greenhouse emissions without increasing drivers 
cognitive workload [12]. Several authors [5] [6] [13] have suggested that feedback from diverse eco-driving systems are recommendable to support users in changing their driving habits and reducing energy consumption in EV.

However, there is an important problem when designing new interface concepts: they require the user to accept the new technology in order to make it successful. Therefore, it is of great importance to discover at a very early stage of development which issues in system design are decreasing the acceptance of the new systems [14].

When designing an eco-driving system in order to increase its acceptability, the rate of learning of eco-driving skills during experience with such a system is an important factor to consider. This will allow the delivery of information to be tailored to optimise learning, and will also allow identification of the point in time at which it is appropriate to reduce or eliminate the guidance to prevent the presentation of redundant in vehicle information [15]. In fact, if advice is provided too frequently, this may become annoying for drivers, therefore influencing overall acceptance and ultimately engagement with the system. A key premise behind the eco-Driver project is that drivers who are able to learn eco-driving skills readily do not need constant eco-driving support.

Another important consideration when designing an eco-driving assistance system for prolonged use is the selection of the most appropriate-most effective and least distracting-modality for the system interface. Currently, the majority of the systems on the market rely on the provision of visual information to the driver [16]. Whilst this is an effective method for the transmission of detailed driving-related information, it also has the potential to overload drivers and distract them from the primary driving task [7]. The negative impact of competing visual tasks on driving performance has been consistently reported, with impairment observed in driver reaction times [17] [18], event detection [19] and lateral control [20].

Whereas prior work has demonstrated a reduction in the distracting impacts of a visual eco-driving interface when combined with a complementary audio signal [7], there is substantial evidence in the literature of adverse effects of an auditory task on driving performance measures such as brake reaction time [21] [22] [23], longitudinal control [24] [25], event detection [23] and steering performance [26]. This suggests a need to consider an alternative presentation modality: haptic feedback.

Haptic gas pedals have been used before in a number of in-vehicle applications such as forward collision warning systems [27] and speed management systems [28] to produce favourable effects on driving performance, as suggested by Hibberd et al. [7]. Birrell, Young, \& Weldon [29] also found positive changes to drivers' behaviour compared to baseline condition, when they evaluated a haptic accelerator pedal's effects on driving performance and perceived workload. They also reported a decrease in subjective workload when driving with the haptic pedal, thus concluding that haptic modality was beneficial in this context as it does not encroach on other attention resource pools that are used in driving 
(i.e. mainly visual). Furthermore, other modalities of haptic feedback have also been tested and showed similar results, for instance Spiessl \& Hussmann [30] assessing error recognition in automated driving used haptic steering-wheel feedback to provide the participant with useful information about the vehicle's trajectory. They found that participants required less time to redirect their attention towards the road after an automation error with haptic feedback. In other words, use of haptic feedback kept drivers more engaged in driving tasks.

Thus, the main objective in the present study is to test the effectiveness, acceptance and workload of Force (FHGP) and Stiffness (SHGP) haptic gas pedals combined with the Full ecoDriver System. Expectations are that haptic gas pedals will help produce eco-driving behaviours and reduce drivers' cognitive workload, which would also increase their acceptance [29]. It is expected that when using a different sensorial channel-the haptic channel-information will be processed faster than when presented in visual modalities, as suggested by Wickens [31] in his multiple resource theory, and consequently drivers' workload should be lower.

The main hypotheses are:

- Experimental conditions should favour maintaining a steadier speed.

- Speed differences are expected before events between baseline and experimental conditions.

- Speed during event should decrease in experimental conditions.

- Speed during event should decrease with HGP modalities more than with FeDS.

- HGP modalities should register equal or lower workload values compared to FeDS.

- FeDS should register higher general workload values compared to baseline conditions.

- HGPs would obtain more favourable acceptance and satisfaction results compared to FeDS in the van der Laan Acceptance scale.

\section{Method}

The design of this research takes as a methodological reference the study conducted by Hibberd, Jamson, \& Jamson [7] at the University of Leeds. They focused on the interaction between the driver and their vehicle, looking at what type of eco-driving information is easy to use and learn whilst not compromising safety. They tested drivers' ability to follow eco-driving advice accurately; as well as their tendency to prioritise this over driving safety. FeDS (visual feedback) with FHGP and SHGP (haptic feedback) were tested in the Leeds University's driving simulator in order to evaluate both visual and haptic eco-driving feedback systems. They found that eco-driving advice improved driving performance, and that visual feedback was the most effective. However, this modality increased subjective workload as it reduced driving attention to the forward view. Although haptic force feedback's effect on subjective workload was lower, it was less effective than a visual feedback system. 


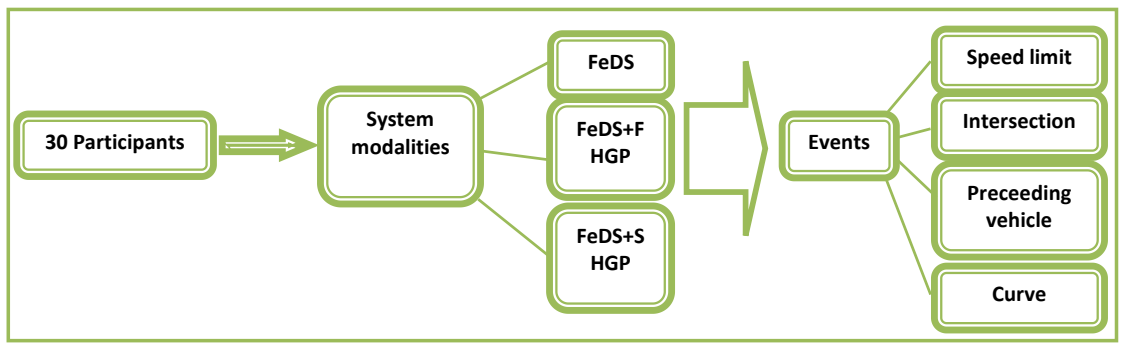

Figure 1. Method flow block diagram.

For this reason, in the present study (Figure 1) the main intention was to bring this test to a real-world driving situation and compare the main results of both studies. Speed parameters (in $\mathrm{km} / \mathrm{h}$ ) before, during and after each event (i.e. speed limit change, preceding vehicle, curve and intersection) in both baseline and experimental conditions were registered.

\subsection{Participants}

Participants were 30 CTAG workers, of whom 26 were men and four were women. Their average age was 33 years old $(\mathrm{M}=33.67 ; \mathrm{SD}=5.55)$. All of them received $20 €$ as an economic compensation when they finished the trials. None of the 30 participants were familiar with using haptic gas pedals, though 25 of them had already participated in a previous study with the Full ecoDriver system and had already driven the Nissan Leaf used in the present study. The other five participants were recruited later to replace other participants who were unable to be involved owing to reasons outside the research. These five newly recruited participants had no previous experience with the car, nor with the ecoDriver system, nor with the use of haptic pedals.

\subsection{Apparatus}

\subsubsection{Full ecoDriver System}

The Full ecoDriver System is based on energy algorithms. The model uses data from the Controller Area Network (CAN) bus of the vehicle, Global Positioning System (GPS), a map database and radar to provide guidance on how to achieve optimal energy efficiency through accelerator pedal usage and to create driving recommendations for the user linked to the functions to be tested. This advice recommends lifting the foot off the accelerator pedal. It is the driver's decision whether to obey the eco-driving guidance if it advises them to behave in a way which might compromise their safety. Once the event is finished, the system provides feedback about the driver's ecoDriver reaction, showing a score on the display by colouring from 0 to 5 stars.

In addition, at any time, the system provides:

- Gear information: the current gear engaged and the recommended gear shown through arrows

- Speedometer information: a blue needle represents the current speed and a green area with the eco speed is also shown. This best speed for an ecodriving style depends on the speed limits, vehicle configuration, power train and the 
vehicle ahead.

The functions tested in this controlled test are:

- Preceding vehicle detection: the system detects a vehicle ahead driving slower than the ecoDriver vehicle when the speed of the ecoDriver vehicle is higher than $40 \mathrm{~km} / \mathrm{h}$ and the distance to the vehicle ahead is more than $20 \mathrm{~m}$.

The Human-Machine Interface (HMI) application (see Figure 2) shows a popup on the screen for six seconds which recommends the driver to decrease pressure on the accelerator pedal. The aim of the system with this recommendation is to support the driver in a progressive deceleration using the engine brake.

- Approaching an intersection: The use of a map database enables the system to receive data about the approaching horizon. This makes it possible to know when the ecoDriver vehicle is getting closer to the intersection (see Figure 3). The information on the pop-up recommends releasing the accelerator pedal for a progressive deceleration using the engine brake while approaching the intersection.

- Approaching a stretch of road with a lower speed limit. the map database also offers information about the presence of speed limits and their position (see Figure 4). This makes it possible to know when the ecoDriver vehicle is getting closer to a speed limit. The HMI application shows the pop-up of the figure only when the speed of the ecoDriver vehicle is higher than the speed limit.

- Approaching a curve: The map database indicates the presence of curves and their position (see Figure 5). The system reacts to this event when approaching the curve if the speed of the ecoDriver vehicle is higher than the "safe speed" to approach the curve. The HMI application shows the pop-up of the figure only when the speed of the ecoDriver vehicle is higher than the "safe speed" of the curve. The information on the pop-up recommends releasing the accelerator pedal for a progressive deceleration using the engine brake approaching the curve. Once the driver has carried out the system's recommendation and the vehicle has entered the curve, the system gives feedback showing a score on the driver's behaviour.

In this study, the haptic gas pedal provides additional feedback and emphasises the information provided by the HMI. Two different stages are implemented:

- Force mode: applies a resisting force when some of the FeDS functions consider that the user should stop pressing the accelerator pedal.

- Vibration mode: the motor simulates a vibration when any of the FeDS demands it.

\subsubsection{FeDS Components}

The Full ecoDriver System was integrated in a 2010 Nissan Leaf, of which the main components are:

- Radar: Front radar was integrated in the vehicle to implement the Preceding Vehicle Detection function. 


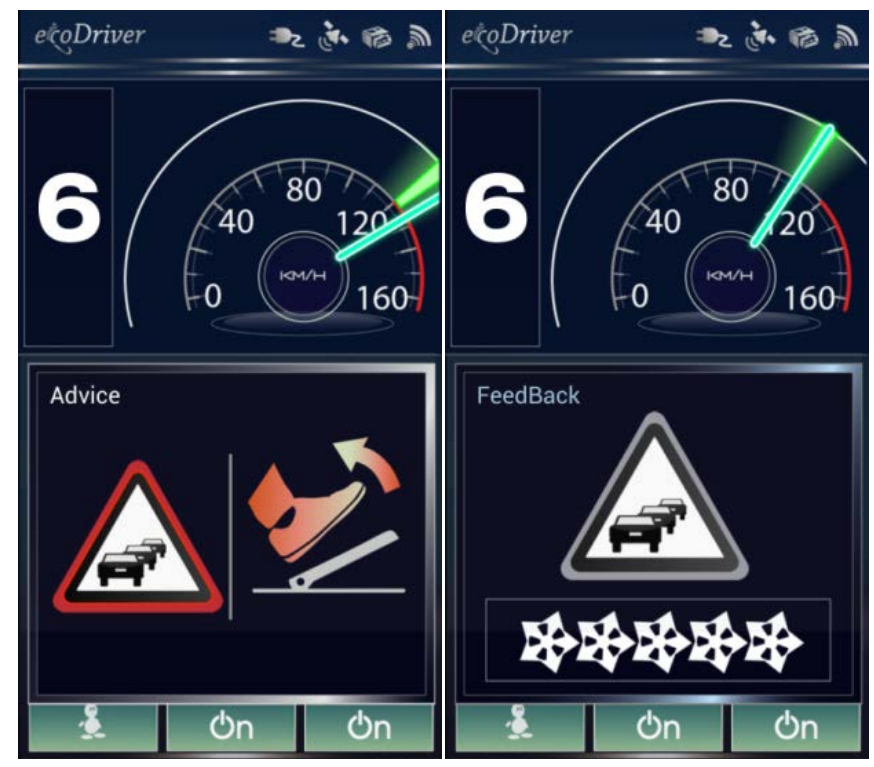

Figure 2. Advice and feedback for preceding vehicle detection.
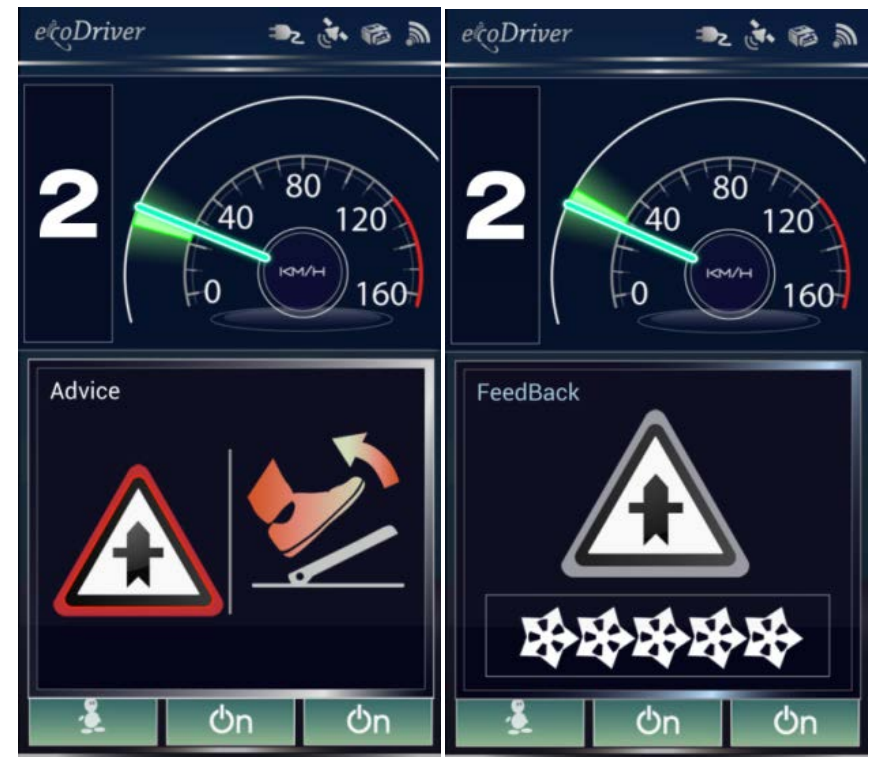

Figure 3. Advice and feedback for approaching an intersection.

- Car PC: with a map database and FeDS software.

- Smartphone: this device receives information from the car's PC via Wi-Fi and shows it in a visual and user-friendly way. It was attached to the front windscreen (see Figure 6).

- CTAG datalogger: this is the logging system. The datalogger is connected to the CAN bus of the vehicle, radar and a GPS antenna, and gathers all this information at $10 \mathrm{~Hz}$.

- Haptic gas pedal: an electric motor was attached to the accelerator pedal to simulate the behaviour of a haptic pedal. This motor is controlled by a PC that receives the ecoDriver messages from the Car PC. The pedal could be turned on and off with a switcher. 


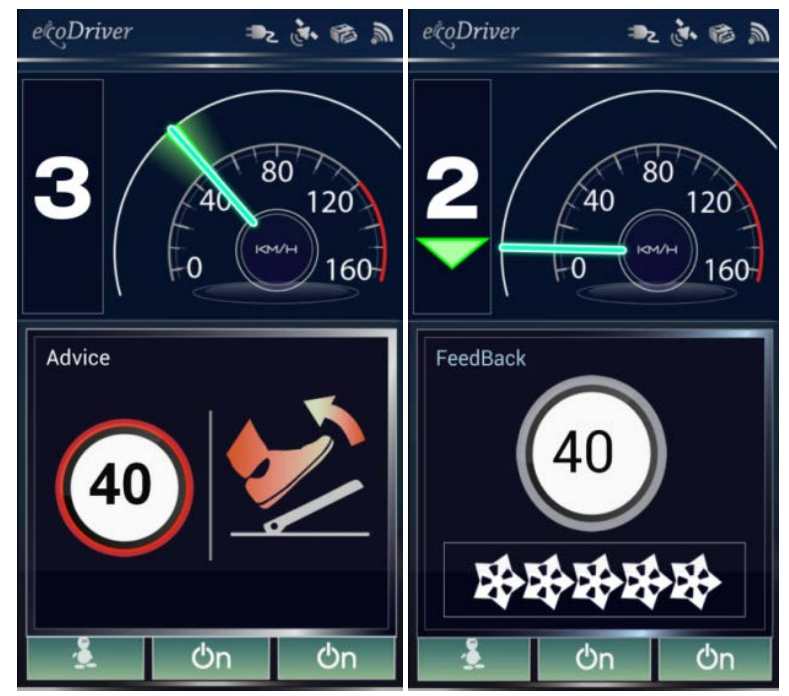

Figure 4. Advice and feedback when approaching a lower speed limit.

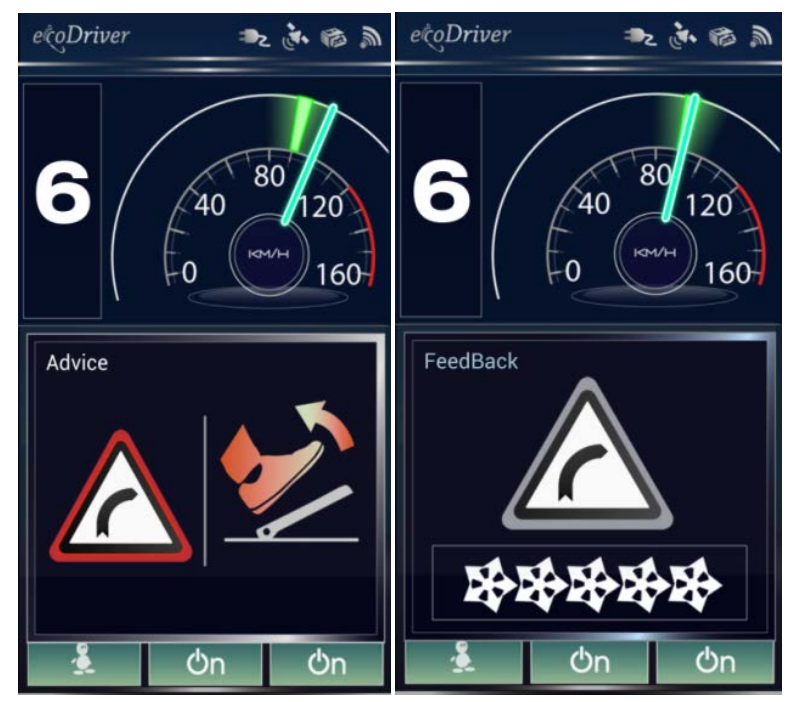

Figure 5. Advice and feedback when approaching a curve.

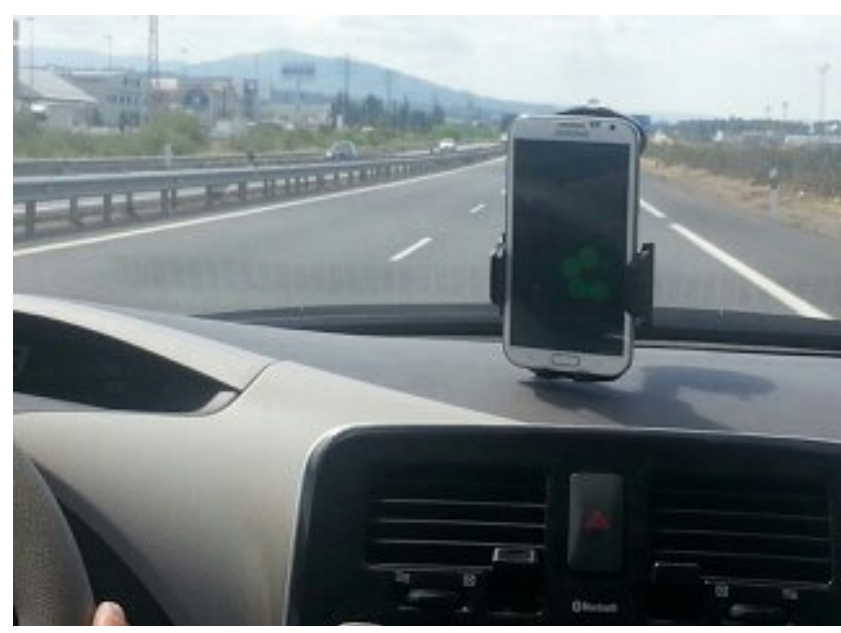

Figure 6. Smartphone used as a nomadic device displaying FeDS. 


\subsubsection{The Track}

Trials had been carried out on an open road track combining motorway and inter-urban stretch which allowed several possible scenarios: curves, intersection/roundabout, speed limits and motorway stretch (see Figure 7). The track started at a roundabout (A), followed by and incorporation to the traffic (B). Then, participants drove through the dual carriageway with speed limited to 120 kilometres per hour (C). At a certain point, the speed limit changed from 120 $\mathrm{km} / \mathrm{h}$ to $90 \mathrm{~km} / \mathrm{h}(\mathrm{D})$. After that, they had to leave the dual carriageway and deal with a roundabout (E), followed by a making a U-turn on a conventional road (F). Afterwards, drivers had to incorporate to the dual carriageway back to point A (G). The dual carriageway driving with speed was limited to $120 \mathrm{~km} / \mathrm{h}(\mathrm{H})$. Finally, they had to leave the dual carriageway and stop at point A (I).

\subsubsection{Questionnaires and Scales}

Questionnaires utilised included a battery of items to establish the profile of the sample relating to socio-demographic data such as age, gender, driver experience (years), annual mileage $(\mathrm{km})$ and employment. It also included items related to in-vehicle technologies experience (e.g. using GPS navigation, Cruise Control, parking aids, etc.), willingness to use new technologies and attitudes towards efficient and green behaviour.

Secondly, they also included completing the NASA-Task Load Index after finishing each of five trials. This scale was primarily developed to evaluate workload in aviation. However, 20 years later it is being used in several fields and studies with the same purpose: namely, evaluating cognitive workload in humans while performing a task. In the transportation field it has also been used in many different studies, such as for evaluating driving distractions [32] [33] [34]

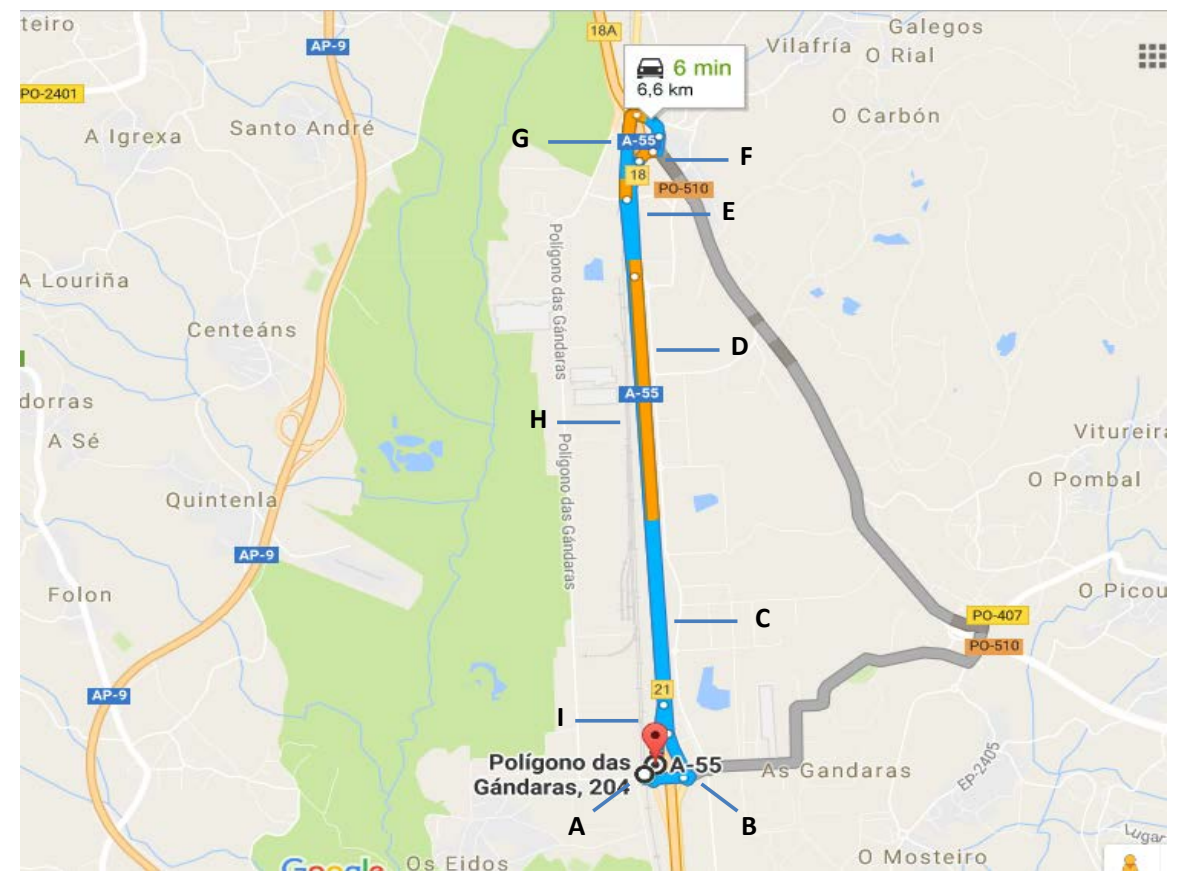

Figure 7. Open track used in trials. Image provided by Google Maps. 
or assessing in-vehicle assistance systems [7] [29] [35]. In this case, workload is defined as "a term that represents the cost of accomplishing mission requirements for the human operator" [36]. NASA-TLX consists of six subscales that represent independent clusters of variables: Mental demand, Physical demand, Temporal demand, Frustration level, Effort, and Performance.

In the experimental conditions, the Van der Laan acceptance scale [37] was included. It has been used and validated in several transport studies such as with a Tutoring and Enforcement system [38] [39], Intelligent Cruise Control [40] [41] and with a Collision Avoidance System [42]. This scale is directed towards evaluation of user-acceptance of the system's ergonomics, and includes a set of items related with the FeDS system's perception. Individual item scores run from -2 to +2 , except items 3, 6 and 8 which are reversed compared to the other items in order to avoid automatic responses. The first subscale contains an assessment in terms of useful, good, effective, assisting and raising alertness, and could be interpreted as denoting the system's usefulness. The second subscale contains an assessment in terms of pleasant, nice, likeable and desirable, and could be interpreted as reflecting satisfaction with the system.

\subsection{Research Design}

A multifactorial repeated measures design was produced. Independent variables were: the FeDS with the traditional accelerator pedal; FeDS with FHGP; and FeDS with SHGP. For each independent variable four events were proposed: speed limit, curve, intersection or roundabout, and predecessor vehicle. Dependent variables registered in each situation were the following: vehicle speed during event, vehicle speed five seconds before event, vehicle speed five seconds after event, and participant's cognitive workload and system acceptance.

\subsection{Procedure}

Before initiating each test a previous appointment had been made with each participant. Participants were welcomed in CTAG's garage. First they had to show they had their driving license in order. Next, when they entered the vehicle they were instructed how the vehicle and the ecoDriver system worked. After that, they were also informed about the nature of the study and that they were going to use a vehicle with a three-level haptic gas pedal: standard mode, force mode and stiffness mode. The test started once each participant had understood that the haptic pedal was in no way dangerous and that it could be disabled by pushing the brake pedal. The only instruction given was to drive as s/he usually did, respecting all traffic rules. When the participant was ready and had understood all the instructions, they proceeded to leave CTAG's garage and drove to point A (see Figure 6), always following the same route. Eventually, once point A has been reached, the car was stopped in order to initialise the data collection devices. This procedure was repeated in each trial and with each participant.

As with Hibberd et al., (2015) [7] each of the five experimental trials lasted approximately 10 minutes and included the four events. Thus, participants took 
approximately one hour to complete the whole test. Participants performed the same circuit in each experimental condition (see Figure 7).

The first condition was a baseline (baseline 1). In this lap, participants only had to drive as they would usually do, without FeDS nor HGP.

The second lap was the first experimental condition. Participants had to drive as they would usually do, but this time using the FeDS, or using the FeDS with one of both HGP (this is Force gas pedal or haptic gas Stiffness pedal). Each lap's experimental conditions were counterbalanced across all participants.

The third lap was the second experimental condition. Participants had to drive as they would usually do; using the FeDS, or using the FeDS with HGP. Conditions were randomised, thereby avoiding the repetition of the previous condition in lap 2.

The fourth lap was the third experimental condition. Participants had to drive as they would usually do using the FeDS, or using the FeDS with HGP. Conditions were randomised, so repeating the previous condition in laps 2 and 3 was again avoided.

The last lap was another baseline condition (baseline 2) introduced to investigate the possible appearance of learning effects. Participants only had to drive as they would usually do neither without the FeDS nor with HGP.

NASA-TLX questionnaires were filled out after each experimental condition in order to achieve greater accuracy. Other questionnaires were filled out on the same day or on following days, at most one week later.

\section{Results}

The need to register a type of widely differing variables during this study has been previously explained. A sample profile was composed with participants' socio-demographic data, drivers' experience using driving assistance technologies, participants' willingness to use technology and their attitude towards green behaviour.

Furthermore, driving speed $(\mathrm{km} / \mathrm{h})$ before, during and after the events detected by the FeDS was also registered. These events were curve, intersection, speed limit and preceding vehicle.

Lastly, a set of several questionnaires and scales was used to register participants' subjective information including workload (NASA-TLX) and acceptance (Van der Laan Scale). The main outcomes are presented itemised below.

\subsection{Sample Profile}

Demographic data used in this study included participants' age, gender and annual mileage. Moreover, drivers' experience using driving assistance technology such as route navigation, cruise control, parking aids, speed warnings, etc., participants' willingness to use technology and their attitude towards environmentally-friendly behaviour was also included. This information will be helpful to better understand and interpret the main results. 


\subsubsection{Demographics}

The sample was made up of 26 men and four women, their mean age being 33 years old $(M=33.67$; $S D=5.55)$ as indicated previously in section 2 (see Figure 8) for more sample distribution details). Furthermore, their mean annual mileage was $20600 \mathrm{~km}$ per year ( $\mathrm{SD}=8319.48)$, where the maximum was $40000 \mathrm{~km}$ per year and the minimum was $6000 \mathrm{~km}$ per year. This suggests that participants spent more time driving than the average Spanish driver, as the mean mileage in Spain in 2014 was 9126 kilometres per year [43]. Moreover, participants' mean driving experience was $M=14.33$ years $(S D=5.18)$, which suggests that the sample was primarily formed by young but experienced drivers. This information might be relevant to understanding the main results, as participants were used to driving regularly and had experience with some in-vehicle systems.

\subsubsection{Experience with Technology}

Participants were not novice drivers. They were young people who habitually drove more kilometres per year than the average driver in Spain, and they were also used to being involved with in-vehicle technology. They mainly had experience with route navigation, cruise control and reverse parking aid; as these are the most common systems installed in new vehicles over the last five years. This suggests that participants were used to driving cars recently manufactured which incorporated the most recent in-vehicle technology. Other participants also had experience with other recently-developed systems such as speed limit change and fuel efficiency advisor, and which are especially related to the FeDS tested in the present study. Lastly, a few participants had experience with other brand

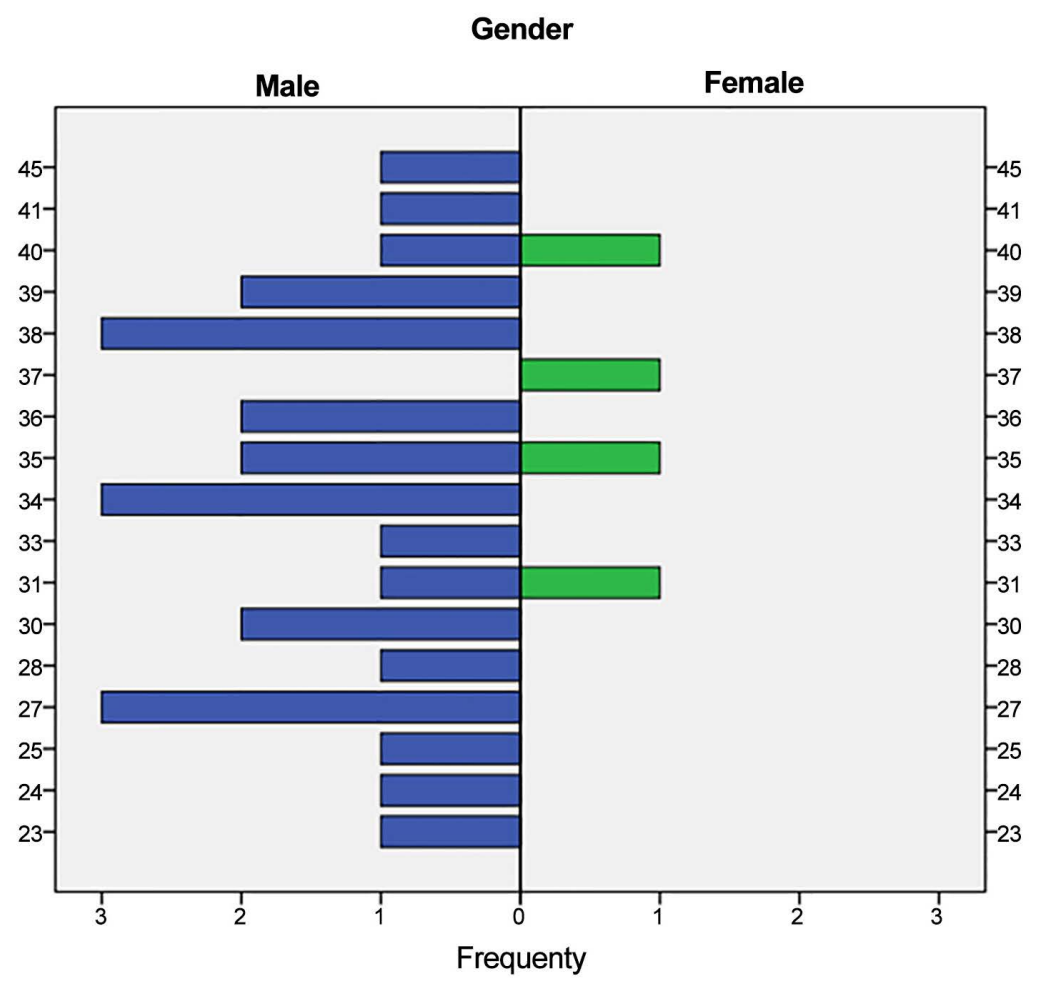

Figure 8. Demographics: age and gender. 
new technology, and although they represent one out of four participants, this suggests that the sample drivers in the present study are up-to-date with invehicle technology.

\subsubsection{Technology Readiness}

This scale is part of the pre-exposure questionnaire pack and was previously used by Jamson et al. [10] in the ecoDriver D42.1-Evaluation of effectiveness subproject. It contains items formed by sentences describing people's attitudes towards willingness to use technology. The highest-rated items were statements related with the freedom and flexibility that technology offers; how technology can help to increase efficiency, and also the concept of technology as a personal challenge to enjoy, as well as learning how to use it. On the other hand, the items rated with the strongest disagreement are statements related to the consequences of misusing technology, such as the dangers of carrying out financial operations on line. This is in accordance with the highest rated items in this scale, indicating that participants were really familiar with the latest technology as they knew quite well how technology can be misused nowadays.

\subsubsection{Attitudes towards Green Behaviour}

This scale also forms part of the pre-exposure questionnaire set and was also used by Jamson et al. [10] together with the Technology readiness scale with the purpose of classifying drivers regarding their driving style and habits. The scale contains items formed by sentences describing people's attitudes towards environmentally-friendly behaviour. Participants strongly agreed that they had a good knowledge of environmentally-friendly behaviour and that they were interested in saving as much energy as possible while driving. In contrast, they did not think that eco-driving was currently a common practice with drivers; perhaps participants thought that environmentally-friendly behaviour is not often ingrained in most drivers' minds. This suggests that in future actions increasing the interest in being an eco-driver should be taken into account.

\subsection{Events}

A one-way intra-groups multivariate analysis of variance $F=\frac{S^{2} X}{S^{2} Y}$ was performed to investigate speed differences in the following events: curve, speed limits, preceding vehicle and intersection. Three dependent variables were used: speed before, during, and after the event. The independent variable was the FeDS modality. Preliminary assumption testing was conducted to check for normality, linearity and multivariate outliers, homogeneity of variance-covariance matrices, and multicollinearity, with no serious violations noted.

\subsubsection{Curve}

See Figure 9, speed in baseline 1 was always higher than other conditions, while experimental conditions showed lower values, especially after the event. FHGP registered the lowest mean speed $[\mathrm{M}=24.17(\mathrm{SD}=1.22)]$, both during the event 
and after $[\mathrm{M}=34.87(\mathrm{SD}=4.97)]$. The second baseline produced different results; before and during the curve, speed was similar to experimental conditions, although after the event it was almost equal to first baseline.

No statistically significant differences between the mean speed values were found across conditions, indicating that there were no differences in driving speed on curves, with or without FeDS modalities.

\subsubsection{Speed Limit}

An inspection of mean speed scores indicated that the FeDS condition achieved the lowest value $[\mathrm{M}=108.57(\mathrm{SD}=12.76)]$, both before and during the event $[\mathrm{M}$ $=110.82(\mathrm{SD}=12.14)]$. These differences are more appreciable in Figure 10 where mean speed values are represented for each condition. HGPs registered speeds faster than the first baseline, except after the event.

Mean speed statistically significant differences were found, $F(12,572)=4.42$, $\mathrm{p}<0.05$; Wilks' Lambda $=0.79$; partial eta square $=0.08$; between FeDS condition and other conditions, suggesting that visual feedback (FeDS) is more effective than the other system modalities for speed limitation events.

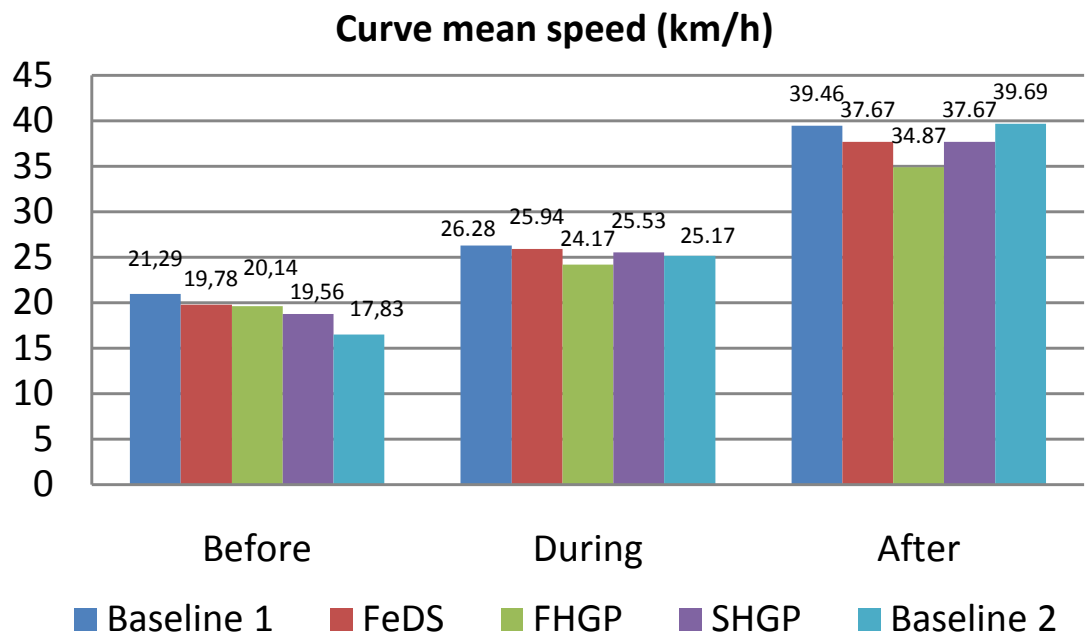

Figure 9. Mean speed values before, during and after curve event for each condition.

Speed limit mean speed $(\mathrm{km} / \mathrm{h})$

115
114
113
112
111
110
109
108
107
106
105

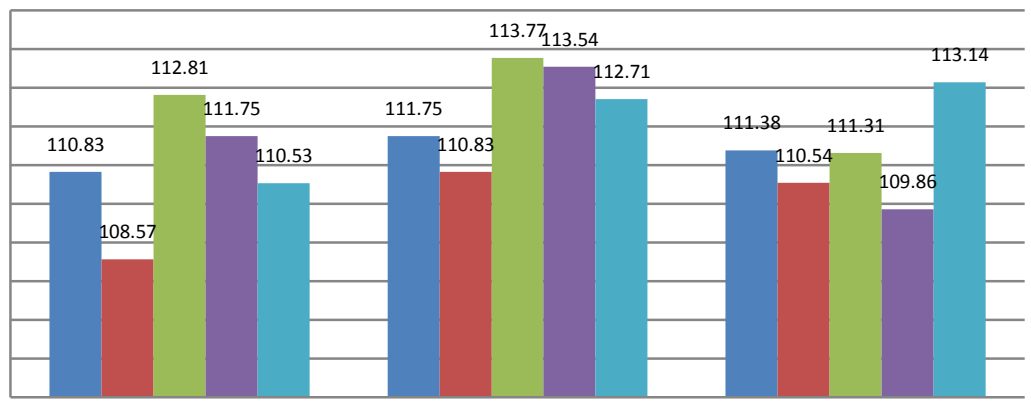

Before

During

After

Baseline $1 \square$ FeDS $\quad$ FHGP $\quad$ SHGP Baseline 2

Figure 10. Mean speed values during, before and after speed limit event. 


\subsubsection{Preceding Vehicle}

A descriptive statistical analysis showed that FHGP registered the lowest speed across all conditions (see Figure 11): before $[\mathrm{M}=87.77$ ( $\mathrm{SD}=17.44$ )], during $[\mathrm{M}=81.21(\mathrm{SD}=23.94)]$ and after $[\mathrm{M}=82.53(\mathrm{SD}=20.30)]$ the preceding vehicle event. In addition, the second baseline showed values more similar to experimental conditions than to baseline 1, suggesting a possible learning effect.

In this condition the data did not fulfil main MANOVA assumptions, as there was a high correlation $(0.8-0.9)$ between dependent variables. Covariance matrices Box test was also lower than $<0.001$, so an ANOVA for each dependent variable was carried out. However, the differences were not statistically significant across conditions.

\subsubsection{Intersection}

The analysis of the mean scores (Figure 12) suggested that FHGP appeared to be the most effective modality for reducing speed in advance and then maintaining a slow speed during and after the intersection event. It resulted in the lowest speed across conditions; before [ $\mathrm{M}=40.06(\mathrm{SD}=12.80)]$, during [ $\mathrm{M}=37.10$ (SD $=6.44)]$ and after it $[\mathrm{M}=31.55(\mathrm{SD}=17.43)]$. Baseline 2 registered very similar values to FeDS and SHGP, except after the event.

The mean speed differences were statistically significant for FHGP modality: F $(12,997.74)=3.51, \mathrm{p}<0.05$; Wilks' Lambda $=0.90$; partial eta square $=0.04$, suggesting that force haptic feedback is more effective than others in intersection events.

\subsection{Subjective Measurements}

In this case data failed to meet the normality assumption, so a non-parametric test for multiple related variables was performed to investigate workload differences between NASA-TLX variables across all conditions. The rating data were analysed using Friedman's ANOVA $\left(x^{2} r=\frac{12}{N k(k+1)}\left[\sum R i^{2}\right]-3 N(k+1)\right)$, where as Wilcoxon tests $\left(W^{+}=\sum_{i=1}^{n} \varnothing i R i\right)$ were used for the post hoc tests of
means.

\subsubsection{NASA-TLX}

Overall, NASA-TLX total score was low in all conditions, as the maximum score was 14.5 out of a total of 60 . Total median scores were analysed for each condition separately (see Figure 13).

Unexpectedly, experimental conditions reported the highest workload values, especially those with HGPs (FHGP Md = 14.5; SHGP Md = 14.2). FeDS median workload values $(\mathrm{Md}=12.7)$ were similar to those observed in Baseline $1(\mathrm{Md}=$ 12.2). Baseline 2 produced the lowest total workload values $(\mathrm{Md}=9.15)$.

\subsubsection{Van der Laan Acceptance Scale}

As data failed to meet the normality assumption, a non-parametric test for multiple related variables was produced to explore Acceptance differences between system modalities. Below, the average scores of the Van der Laan Acceptance 


\section{Preceding vehicle mean speed $(\mathrm{km} / \mathrm{h})$}

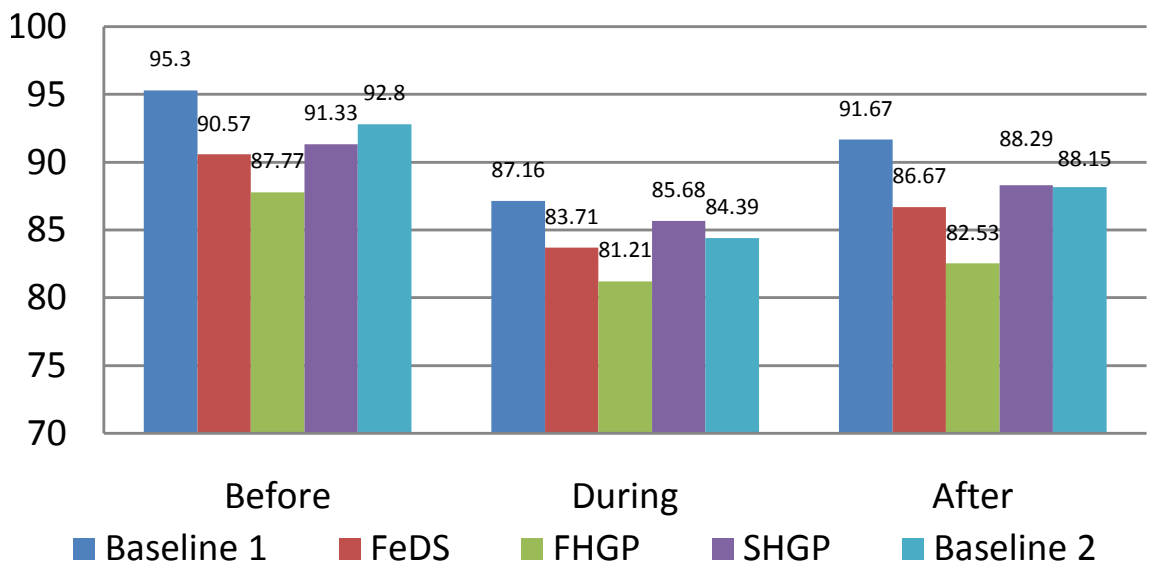

Figure 11. Mean speed values during, before and after preceding vehicle event for each condition.

\section{Intersection mean speed $(\mathrm{km} / \mathrm{h})$}

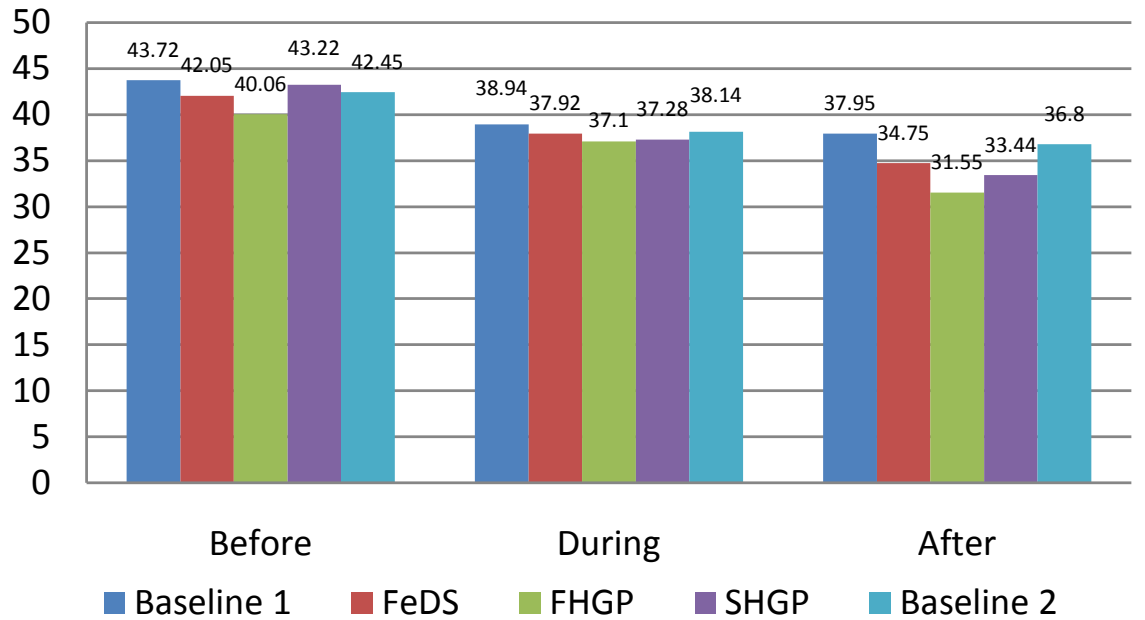

Figure 12. Mean speed values during, before and after intersection event for each condition.

Scale are presented separately in their two different subscales: Usefulness (Table 1) and Satisfaction (Table 2). The reader should remember that the punctuation system is reversed for items bad/good, irritating/likeable and undesirable/desirable, giving a negative punctuation to a positive adjective $(-2$ to +2$)$ and making the results confusing. Table 1 shows that FHGP was rated as the most Useful in the first subscale.

A similar term reversal occurs in Table 2, where FeDS appears to be the most satisfying system modality.

The results of the Friedman Test showed that there was a statistically significant difference in variables: Pleasant $\left.\mathrm{X}^{2}(2, \mathrm{n}=26)=7.79, \mathrm{p}<0.05\right) ; \operatorname{Bad~}^{2}(2, \mathrm{n}$ = 26) = 8.85, $\mathrm{p}<0.05)$; Nice $\left.\mathrm{X}^{2}(2, \mathrm{n}=26)=14.10, \mathrm{p}<0.05\right)$; Irritating $\mathrm{X}^{2}(2, \mathrm{n}=$ 26) $=12.23, \mathrm{p}<0.05)$; Alertness $\left.\mathrm{X}^{2}(2, \mathrm{n}=26)=14.86, \mathrm{p}<0.05\right)$. Thus a Wilcoxon test was applied to explore the size effect with a Bonferroni alpha adjust- 
ment to $0.016(0.05 / 3)$ between these variables. There were statistically significant differences $(\mathrm{p}<0.016)$ between Pleasant, Nice and Irritating values in FeDS and FHGP conditions; and in FeDS and SHGP modalities. There were also statistically significant differences $(\mathrm{p}<0.016)$ in item Alertness between FeDS and SHGP conditions.

Table 1. Van der Laan Acceptance Scale. Usefulness subscale mean scores.

\begin{tabular}{cccc}
\hline & FeDS & FHGP & SHGP \\
Useful & 0.7 & $\mathbf{0 . 8 2}$ & 0.95 \\
Good & 0.56 & 0.64 & 0.07 \\
Effective & 0.52 & 0.86 & 0.78 \\
Assisting & 0.63 & 0.46 & 0.7 \\
Alertness & 0.59 & 1.04 & 1.04 \\
\hline
\end{tabular}

Table 2. Van der Laan Acceptance Scale. Satisfaction subscale mean scores.

\begin{tabular}{cccc}
\hline & FeDS & FHGP & SHGP \\
\hline Pleasant & 0.59 & -0.14 & -0.41 \\
Nice & 0.81 & -0.14 & 0.04 \\
Likeable & 0.41 & -0.18 & -0.3 \\
Desirable & 0.63 & 1.04 & 0.56 \\
\hline
\end{tabular}

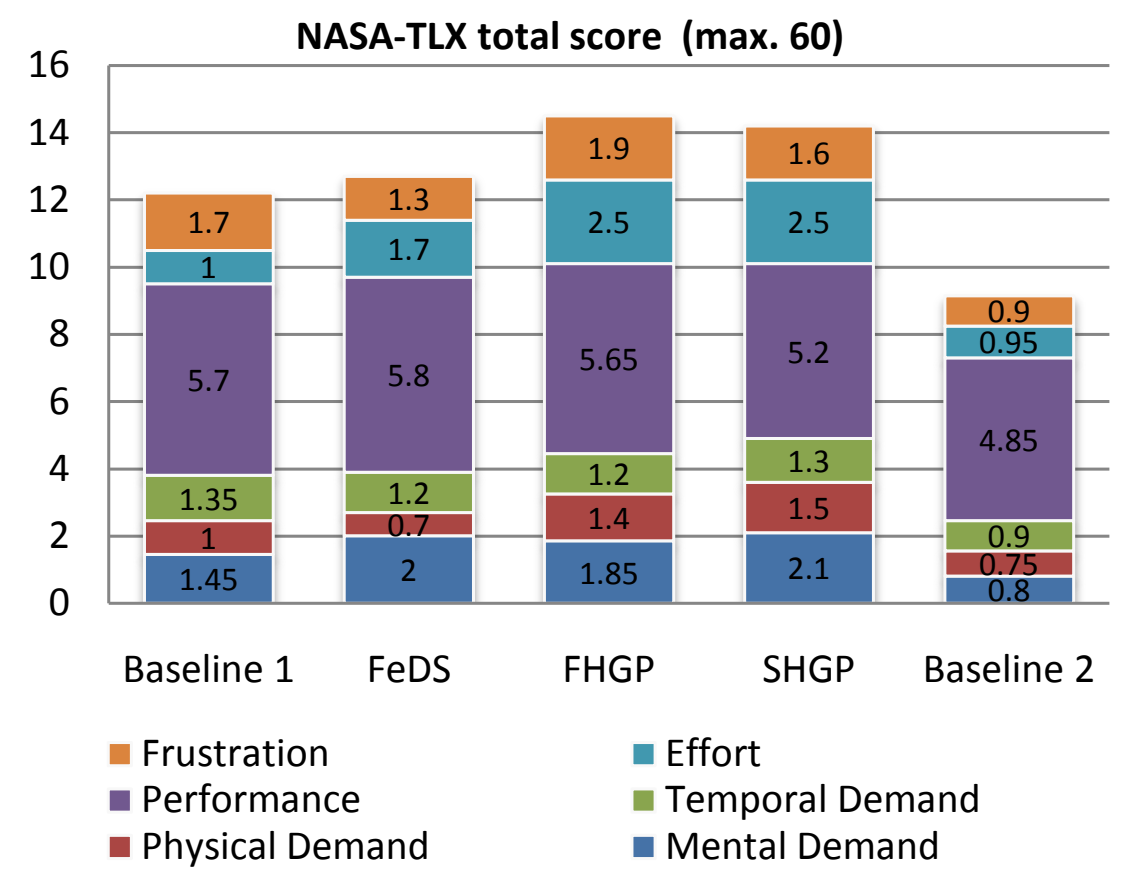

Figure 13. NASA-TLX total median score. 


\section{Discussion}

The initial purpose of the present paper was to test the effectiveness of the FeDS combined with HGPs, to discover whether this combination can teach efficient driving strategies and facilitate drivers' decision-making processes. It was also aimed at assessing whether HGPs help to reduce subjective workload, as the haptic information presented through the pedals should lower visual information overload and therefore decrease subjective workload. It was also necessary to test user acceptance, which would indicate if the product is desirable and affordable for use in real life.

The study's sample profile was mainly composed of young people with considerable driving experience, accustomed to and willing to use new in-vehicle technology. Participants had a positive attitude towards eco-friendly behaviour and were very open to following the advice provided by FeDS. The sample profile was therefore suitable for the purpose of the present study.

It was expected that analysis of the main results obtained in objective measurements, would show that FeDS and HGPs' recommendation shelped drivers to anticipate different events and assisted them with the decision-making process, reducing speed progressively before reaching the given event, in order to drive at the recommended speed while negotiating it.

Firstly, in the Curve event, speed differences were expected between baselines and system modalities before the event. However, no differences were found when analysing data. This could be explained by participants' replies indicating that the curve warning signal displayed in the FeDS device was confusing and did not actually fulfil its purpose since it always signalled a curve to the right, so that when in fact it turned to the left, the warning could confuse the driver. Further studies need to improve the way curve information is displayed in order to resolve this problem. Given these results, there is no clear evidence as to which is the best feedback mode for curves.

For the Speed limit event it was expected that FeDS modalities would help participants to detect speed limitations and avoid exceeding them. As expected, speed was higher during the event than before and after the event; once drivers reached the top speed allowed on the dual carriageway, the system alerted them and they then slowed down immediately. Differences between FeDS and HGP modalities were also found. Before and during the event, FeDS registered the lowest value, whereas, after the event it was the SHGP which afforded the lowest value, followed by the FeDS. These data clearly suggest that FeDS offers the most effective warning to avoid exceeding speed limits. Furthermore, participants agreed that FeDS was really effective and useful for speed management and, especially when combined with HGPs, it was also more satisfying.

In the Preceding vehicle event, speed differences were expected between the first baseline and experimental conditions, and also between FeDS and HGPs. HGPs should help to accelerate driver response on the gas pedal; thus speed after the event with HGPs should be lower than FeDS and baseline 1. Before the event it was expected that speed would be quite similar across all conditions; but dur- 
ing the event it should be lower in experimental conditions because of the FeDS and HGPs effect. However, no differences were found across conditions. Further research is needed in this area, particularly as participants' subjective evaluations suggested that FHGP was really effective and useful for maintaining the safety distance. Nevertheless, many of them also agreed that it was not useful when they tried to overtake a vehicle, or when moving from the slow lane to the fast lane. The pedal should therefore be modified in future investigations in order to avoid these disturbing situations.

Finally, in the Intersection event, speed differences before the event were expected between the first baseline and experimental conditions; as FeDS, and specially HGPs, should help to warn drivers about an imminent intersection and therefore to reduce their speed before reaching the event. Some interesting differences were found across conditions: FHGP registered the lowest values across all conditions, evidencing its effectiveness above the rest. This may be explained because FHGP was more intrusive and "forced" drivers to reduce their speed during the event. Meanwhile, the last baseline showed a similar pattern to experimental conditions, so maybe future studies could investigat whether participants learnt to anticipate the event. These data suggest that FHGP is the most recommendable feedback modality for intersection or roundabout events in terms of safety and efficiency. Assuming that a roundabout should be taken at under $40 \mathrm{~km} / \mathrm{h}$, the FHGP was the only feedback modality which helped drivers to maintain this speed. Nevertheless, it should be noted that participants complained that FHGP was actually less effective and useful in roundabouts as it hampered the natural manoeuvre, hindering acceleration while negotiating the roundabout. So in forthcoming investigations, the pedal needs to be checked and fine-tuned to avoid similar disturbing situations; and to allow the driver full control over the gas pedal during the roundabout manoeuvre.

Having explained the main objective data, subjective measurements will now be discussed. It was expected that this subjective data would support the main findings in the objective data previously covered, and furthermore that it would help to understand the principal limitations and suggestions found in users' opinions.

The first scale to be discussed here is the NASA-TLX scale. This was administered in the expectation of finding equal or higher values for FeDS compared to baseline conditions. HGP modalities were also expected to obtain lower workload values compared to FeDS, as HGP should help to reduce the visual overload produced by FeDS' information display. However, no significant workload differences were found between baseline and experimental conditions, and total workload values were unexpectedly low, as the highest median was 14.5 out of 60 in FHGP condition. Notwithstanding, given that the system tested is a prototype, the feedback provided had its limitations when turning on and off, and the haptic sensation provided may not have been the most suitable nor comfortable for drivers. Participants suggested that their perceived workload might be reduced after increased time exposure to HGPs: so further long-term 
research with a wider sample is needed to ascertain in what way FeDS and HGPs increase or reduce workload.

The second scale used for gathering subjective data was the Van der Laan Acceptance scale. It was expected that HGPs would help to increase FeDS acceptability, as pedals reinforced/backed up the information provided by the visual channel and made it easier to follow the eco-driving advice displayed. Indeed, the tendencies observed indicate that the FeDS was in many aspects more acceptable than both HGPs. Significant differences observed between system modalities suggested that FeDS was more pleasant, nice, desirable and likeable than both HGPs, implying that the HGPs should be improved to make them less annoying for users.

As an alternative, if turning on the FHGP were smoother and less abrupt, this would help to increase its acceptance. In fact, FHGP was found to be the most useful and effective feedback modality for learning eco-driving strategies-so improving the force feedback in future investigations in order to make it more acceptable for drivers would certainly be worthwhile.

Regarding "likeability" differences, one reason why FHGP was perceived as more Irritating may again be due to its abrupt activation. Some participants pointed out that such an aggressive pedal movement with no previous warning, was confusing, leading them to think that the pedal was broken.

On the other hand, "alertness" differences between FeDS and SHGP suggest that SHGP is a better solution than FeDS for raising drivers' alertness, which is in agreement with the initial purpose of this feedback modality. SHGP was also the most "assisting" feedback modality, according to reports provided by some participants. They felt that SHGP was more effective as a warning system than other feedback modalities, but not when learning eco-driving strategies. This suggests that SHGP might be a good system to implement in terms of safe driving as a rapid warning system. However, similarly to FHGP, its main limitation in the present study resides in its tuning. SHGP was considered as a "bad" system modality compared to others. Some participants pointed out in the free text responses that employing a different vibration pattern, similar to that currently used in smartphones, would make the SHGP friendlier and more intuitive.

\section{Conclusions}

This was a first study performed to test and validate the FeDS and its haptic gas pedal modalities in real driving conditions, in terms of effectiveness and, ultimately, driving safety. Finding significant differences in a sample of participants well accustomed to trying out new in-vehicle systems suggests that in any future research with samples of quite average drivers, these differences could prove to be even more remarkable.

Overall, the main results evidence that the FeDS visual feedback and its FHGP modality provide the best guidance for saving energy and, in many cases, increasing safety. The FeDS visual feedback is the most recommendable modality for speed management and energy efficiency, as it provides a helpful aid to deci- 
sion-making and learning processes for eco-driving strategies. However, the FHGP feedback modality is mainly recommendable at intersections or roundabouts. Participants' subjective assessments clearly support these main findings. Workload measurements evidence that despite the need to improve some features, the visual feedback provided by the FeDS and the haptic feedback provided by the HGPs do not substantially increase perceived workload. In fact, those feedback modalities were well accepted in terms of usefulness and satisfaction. Although the main system design limitations resulted in both being awarded unfavourable "likeability" results. However, being optimistic, system improvement is possible, so it is to be expected that in further research drivers would eventually be satisfied and would request installation of these systems in their own vehicles as another on-board aid system.

One more relevant result that cannot be ignored is the learning effect observed in the second baseline. It is very promising for FeDS to generate a learning effect in drivers after approximately just one hour driving with it, but in fact, some drivers also showed an eco-driving learning process in the second baseline. This effect had also been observed previously in Beusen et al. [44] who studied the impact of long-term exposure to an eco-driver system and observed lasting differences among drivers, most of whom made permanent improvements to their driving habits. Although such durable differences have not been studied here, they clearly support the principal findings in the present study. This offers new evidence to support FeDS' main purpose which is to reduce energy consumption through efficient driving strategies and facilitate drivers' decisionmaking processes through different feedback modalities.

All in all, the main results discussed here are only partly in agreement with previous ecoDriver research that tested the FeDS system in driving simulators. Hibberd et al. [7] found that visual feedback was more effective than haptic, but increased subjective workload, whereas this study suggested that visual feedback did not increas workload when compared to haptic feedback: both were similarly effective. Jamson et al. [15] found that FHGP was the most effective modality for energy efficiency in scenarios where drivers were required to decelerate; which is in agreement with the results found here in the intersection event. However, further study by Jamson et al. [9] demonstrated the benefits of both visual and haptic systems for providing eco driving feedback on efficient accelerator pedal usage.

For future research, the next step is to compare other feedback modalities in real driving conditions, for instance, testing the FeDS with visual and auditory feedback modalities, as auditory information may be useful in some circumstances where visual information causes overload. It would also be interesting to carry out a longitudinal FOT comparing both HGPs specifically for different events. The FHGP could be used in situations where it has shown its effectiveness, but SHGP could be tested in new scenarios as a warning feedback modality.

The author of this study believes that road and transport researchers into ecodriving solutions should concentrate their efforts on performing FOTs in order 
to validate the most effective feedback modalities and to integrate these into production vehicles incorporating these solutions into our daily life on the road.

\section{Acknowledgements}

This paper is part of the author's Master's Thesis and has been produced in close collaboration with the Automotive Technology Centre of Galicia (CTAG). This material is based upon work supported by ecoDriver project (FP7-ICT 288611).

\section{References}

[1] European Comission (2012) Transportation Sector Emissions in the European Union. http://ec.europa.eu/clima/policies/transport/index_en.htm

[2] Birrell, S., Simpkin, B., Scridon, S. and Rollenitz, L. (2011) Energy Efficient Vehicles for Road Transport-EE-VERT.

http://www.ee-vert.net/Documents/D3.2.3_The_influence_of_driver_behaviour_an d_the_use_of_ITS_on_fuel_consumption.pdf

[3] Kuriyama, M., Yamamoto, S. and Miyatake, M. (2010) Theoretical Study on EcoDriving Technique for an Electric Vehicle with Dynamic Programming. 2010 Joint International Conference on Power Electronics, Drives and Energy Systems \& 2010 Power India, New Delhi, 20-23 December 2010, 5-8.

[4] Miyatake, M., Kuriyama, M. and Takeda, Y. (2011) Theoretical Study on Eco-Driving Technique for an Electric Vehicle Considering Traffic Signals. Proceedings of the International Conference on Power Electronics and Drive Systems, Singapore, 5-8 December 2011, 733-738.

[5] Beloufa, S., Vailleau, B., Boucheix, J.-M., Kemeny, A. and Merienne, F. (2014) EcoDriving with Electric Cars: Effect of Continuous and On-Demand feedback on Driving Behavior and Safety. 5th International Conference on Applied Human Factors and Ergonomics, Krakow, 19-23 July 2014, 158-164.

https://hal.archives-ouvertes.fr/hal-01197472

[6] Felicitas, M. (2013) Optimal Energy Utilization in Conventional, Electric and Hybrid Vehicles and Its Application to Eco Driving. Dissertation, University of Lyon, Lyon.

[7] Hibberd, D.L., Jamson, A.H. and Jamson, S.L. (2015) The Design of an In-Vehicle Assistance System to Support Eco-Driving. Transportation Research Part C: Emerging Technologies, 58, 732-748. https://doi.org/10.1016/j.trc.2015.04.013

[8] Hof, T., Conde, L., Garcia, E., Iviglia, A., Jopson, A., Lai, F., Zlocki, A., et al. (2013) D11.1: A State of the Art Review and Users' Expectations. ecoDriver Project. www.ecodriver-project.eu

[9] Jamson, H., Hibberd, D.L. and Merat, N. (2015) Interface Design Considerations for an In-Vehicle Eco-Driving Assistance System. Transportation Research Part C: Emerging Technologies, 58, 642-656. https://doi.org/10.1016/j.trc.2014.12.008

[10] Jamson, S., Kappe, B. and Louw, T. (2014) D42.1 Performance Indicators and Acceptance Analysis Plan. ecoDriver Project.

[11] Seewald, P. and Stuiver, A. (2014) D13.1 : Evaluation Plan and Scenario Definition. ecoDriver Project. www.ecodriver-project.eu

[12] Birrell, S., Fowkes, M. and Jennings, P. (2014) Effect of Using an In-Vehicle Smart Driving Aid on Real-World Driver Performance. IEEE Transactions on Intelligent Transportation Systems, 15, 1801-1810. https://doi.org/10.1109/TITS.2014.2328357

[13] Franke, T., Arend, M.G., McIlroy, R.C. and Stanton, N.A. (2016) Ecodriving in Hy- 
brid Electric Vehicles-Exploring Challenges for User-Energy Interaction. Applied Ergonomics, 55, 33-45. https://doi.org/10.1016/j.apergo.2016.01.007

[14] Meschtscherjakov, A., Wilfinger, D., Scherndl, T. and Tscheligi, M. (2009) Acceptance of future Persuasive In-Car Interfaces towards a More Economic Driving Behaviour. Proceedings of the 1 st International Conference on Automotive User Interfaces and Interactive Vehicular Applications, Essen, 21-22 September 2009, 8188. https://doi.org/10.1145/1620509.1620526

[15] Jamson, S., Hibberd, D.L. and Jamson, A.H. (2015) Drivers' Ability to Learn EcoDriving Skills. Effects on Fuel Efficient and Safe Driving Behaviour. Drivers' Ability Transportation Research Part C: Emerging Technologies, 58, 657-668. https://doi.org/10.1016/j.trc.2015.02.004

[16] Graving, J.S. and Rakauskas, M.E. (2010) A Binary Response Method to Determine the Usability of Seven In-Vehicle Fuel Economy Displays. Proceedings of the Human Factors and Ergonomics Society Annual Meeting, 54, 1546-1550. https://doi.org/10.1177/154193121005401940

[17] Muhrer, E. and Vollrath, M. (2011) The Effect of Visual and Cognitive Distraction on Driver's Anticipation in a Simulated Car Following Scenario. Transportation Research Part F: Traffic Psychology and Behaviour, 14, 555-566. https://doi.org/10.1016/j.trf.2011.06.003

[18] Summala, H. and Lamble, D. (1998) Driving Experience and Perception of the Lead Car's Braking When Looking at In-Car Targets. Accident Analysis and Prevention, 30, 401-407. https://doi.org/10.1016/S0001-4575(98)00005-0

[19] Olsson, S. and Burns, P.C. (2000) Measuring Driver Visual Distraction with a Peripheral Detection Task.

http://www-nrd.nhtsa.dot.gov/departments/Human\%20Factors/driver-distraction/ $\underline{\mathrm{PDF} / 6 . \mathrm{PDF}}$

[20] Östlund, J. and Nilsson, L. (2004) Deliverable 2-HMI and Safety-Related Driver Performance. Human Machine Interface and the Safety of Traffic in Europe (HASTE) Project.

[21] Alm, H. and Nilsson, L. (1995) The Effects of a Mobile Telephone Task on Driver Behaviour in a Car Following Situation. Accident Analysis \& Prevention, 27, 707715. https://doi.org/10.1016/0001-4575(95)00026-V

[22] Consiglio, W., Driscoll, P., Witte, M. and Berg, W. (2003) Effect of Cellular Telephone Conversations and Other Potential Interference on Reaction Time in a Braking Response. Accident Analysis \& Prevention, 35, 495-500. https://doi.org/10.1016/S0001-4575(02)00027-1

[23] Beede, K.E. and Kass, S.J. (2006) Engrossed in Conversation: The Impact of Cell Phones on Simulated Driving Performance. Accident Analysis \& Prevention, 38, 415-421. https://doi.org/10.1016/j.aap.2005.10.015

[24] Rakauskas, M.E. and Gugerty, L.J. (2004) Effects of Naturalistic Cell Phone Conversations on Driving Performance. Journal of Safety Research, 35, 453-464. https://doi.org/10.1016/j.jsr.2004.06.003

[25] Ranney, T.A. and Harbluk, J.L. (2005) Effects of Voice Technology on Test Track Driving Performance: Implications for Driver Distraction. Human Factors, 47, 439-454. https://doi.org/10.1518/0018720054679515

[26] Reed, M.P. and Green, P.A. (1999) Comparison of Driving Performance On-Road and in a Low-Cost Simulator Using a Concurrent Telephone. Ergonomics, 42, 1015-1037. https://doi.org/10.1080/001401399185117

[27] De Rosario, H. and Louredo, M. (2010) Efficacy and Feeling of a Vibrotactile Fron- 
tal Collision Warning Implemented in a Haptic Pedal. Transportation Research Part F: Traffic Psychology and Behaviour, 13, 80-91. https://doi.org/10.1016/j.trf.2009.11.003

[28] Várhelyi, A. and Adell, E. (2008) Auditory and Haptic Systems for In-Car Speed Management-A Comparative Real Life Study. Transportation Research Part F: Traffic Psychology and Behaviour, 11, 445-458.

https://doi.org/10.1016/j.trf.2008.04.003

[29] Birrell, S.A., Young, M.S. and Weldon, A.M. (2013) Vibrotactile Pedals: Provision of Haptic Feedback to Support Economical Driving. Ergonomics, 56, 282-292. https://doi.org/10.1080/00140139.2012.760750

[30] Spiessl, W. and Hussmann, H. (2011) Assessing Error Recognition in Automated Driving. IET Intelligent Transport Systems, 5, 103-111. https://doi.org/10.1049/iet-its.2010.0102

[31] Wickens, C.D. (2008) Multiple Resources and Mental Workload. Human Factors, 50, 449-455. https://doi.org/10.1518/001872008X288394

[32] Harbluk, J.L., Noy, Y.I., Trbovich, P.L. and Eizenman, M. (2007) An On-Road Assessment of Cognitive Distraction: Impacts on Drivers' Visual Behavior and Braking Performance. Accident Analysis and Prevention, 39, 372-379.

https://doi.org/10.1016/j.aap.2006.08.013

[33] Horberry, T., Anderson, J., Regan, M., Triggs, T.J. and Brown, J. (2006) Driver Distraction: The Effects of Concurrent In-Vehicle Tasks, Road Environment Complexity and Age on Driving Performance. Accident Analysis and Prevention, 38, 185 191. https://doi.org/10.1016/j.aap.2005.09.007

[34] Strayer, D., Cooper, J. and Turrill, J. (2013) Measuring Cognitive Distraction in the Automobile. 53 p. http://trid.trb.org/view.aspx?id=1252566

[35] Jeon, M., Davison, B.K., Nees, M., Wilson, J., Walker, B.N. and Street, C. (2009) Enhanced Auditory Menu Cues Improve Dual Task Performance and Are Preferred with In-Vehicle Technologies. Proceedings of the 1st International Conference on Automotive User Interfaces and Interactive Vehicular Applications, Essen, 21-22 September 2009, 91-98. https://doi.org/10.1145/1620509.1620528

[36] Hart, Sandra, G. (2006) NASA-Task Load Index (NASA-TLX). 20 Years Later. Proceedings of the Human Factors and Ergonomics Society Annual Meeting, 50, 904908. https://doi.org/10.1177/154193120605000909

[37] Van Der Laan, J.D., Heino, A. and De Waard, D. (1997) A Simple Procedure for the Assessment of Acceptance of Advanced Transport Telematics. Transportation Research Part C: Emerging Technologies, 5, 1-10.

https://doi.org/10.1016/S0968-090X(96)00025-3

[38] Waard, D.D. and Brookhuis, K.A. (1997) Behavioural Adaptation of Drivers to Warning and Tutoring Messages: Results from an On-The-Road and Simulator Test. International Journal of Heavy Vehicle Systems, 4, 222-234.

[39] De Waard, D., Brookhuis, K.A., Van der Hulst, M. and Van der Laan, J.D. (1994) Behaviour Comparator Prototype Test in a Driving Simulator. Report V2009/ DETER/Deliverable 10 (321B) to the Commission of the European Union, University of Groningen, Traffic Research Centre, the Netherlands.

[40] Hogema, J.H., Van der Horst, A.R.A. and Janssen, W.H. (1994) A Simulator Evaluation of Different Forms of Intelligent Cruise Control. Report 1994 C-30, TNO Human Factors Research Institute, the Netherlands.

[41] Rothengatter, J.A. and Heino, A. (1994) Safety Evaluation of Collision Avoidance Systems. Proceedings of the 1 st World Congress on Applications of Transport Telematics and Intelligent Vehicle-highway Systems, Paris, 24-26 October 1994, 2047 - 
2054.

[42] Janssen, W.H., Brookhuis, K.A. and Kuiken, M. (1993) Simulator and Fiels Evaluation of In-Vehicle Collision Avoidance Systems: Report of the First Year of Research for Nissan. Report 1993 C-46, TNO Human Factors Research Institute, the Netherlands.

[43] Heraldo. (2014) Los españoles reducen el uso del coche y hacen menos de $10000 \mathrm{~km}$ al año. Europa Press, Madrid.

http://www.heraldo.es/noticias/economia/2014/07/06/los_espanoles_reducen_uso_ del_coche_hacen_menos_000_ano_297970_309.html

[44] Beusen, B., Broekx, S., Denys, T., Beckx, C., Degraeuwe, B., Gijsbers, M., Panis, L.I., et al. (2009) Using On-Board Logging Devices to Study the Long-Term Impact of an Eco-Driving Course. Transportation Research Part D: Transport and Environment, 14, 514-520. https://doi.org/10.1016/j.trd.2009.05.009

Submit or recommend next manuscript to SCIRP and we will provide best service for you:

Accepting pre-submission inquiries through Email, Facebook, LinkedIn, Twitter, etc. A wide selection of journals (inclusive of 9 subjects, more than 200 journals)

Providing 24-hour high-quality service

User-friendly online submission system

Fair and swift peer-review system

Efficient typesetting and proofreading procedure

Display of the result of downloads and visits, as well as the number of cited articles

Maximum dissemination of your research work

Submit your manuscript at: http://papersubmission.scirp.org/

Or contact jtts@scirp.org 